University of Nebraska - Lincoln

DigitalCommons@University of Nebraska - Lincoln

Faculty Papers and Publications in Animal

Science

Animal Science Department

2010

\title{
The Economic Effects of Sorting Cattle by Weight and Time of Year into Different Production Systems1
}

D. R. Adams

University of Nebraska-Lincoln

T. J. Klopfenstein

University of Nebraska-Lincoln, tklopfenstein1@unl.edu

G. E. Erickson

University of Nebraska-Lincoln, gerickson4@unl.edu

D. R. Mark

University of Nebraska-Lincoln

Matt K. Luebbe

University of Nebraska-Lincoln, mluebbe2@unl.edu

See next page for additional authors

Follow this and additional works at: https://digitalcommons.unl.edu/animalscifacpub

Part of the Animal Sciences Commons

Adams, D. R.; Klopfenstein, T. J.; Erickson, G. E.; Mark, D. R.; Luebbe, Matt K.; and Griffin, W. A., "The Economic Effects of Sorting Cattle by Weight and Time of Year into Different Production Systems1" (2010). Faculty Papers and Publications in Animal Science. 754.

https://digitalcommons.unl.edu/animalscifacpub/754

This Article is brought to you for free and open access by the Animal Science Department at DigitalCommons@University of Nebraska - Lincoln. It has been accepted for inclusion in Faculty Papers and Publications in Animal Science by an authorized administrator of DigitalCommons@University of Nebraska - Lincoln. 


\section{Authors}

D. R. Adams, T. J. Klopfenstein, G. E. Erickson, D. R. Mark, Matt K. Luebbe, and W. A. Griffin 


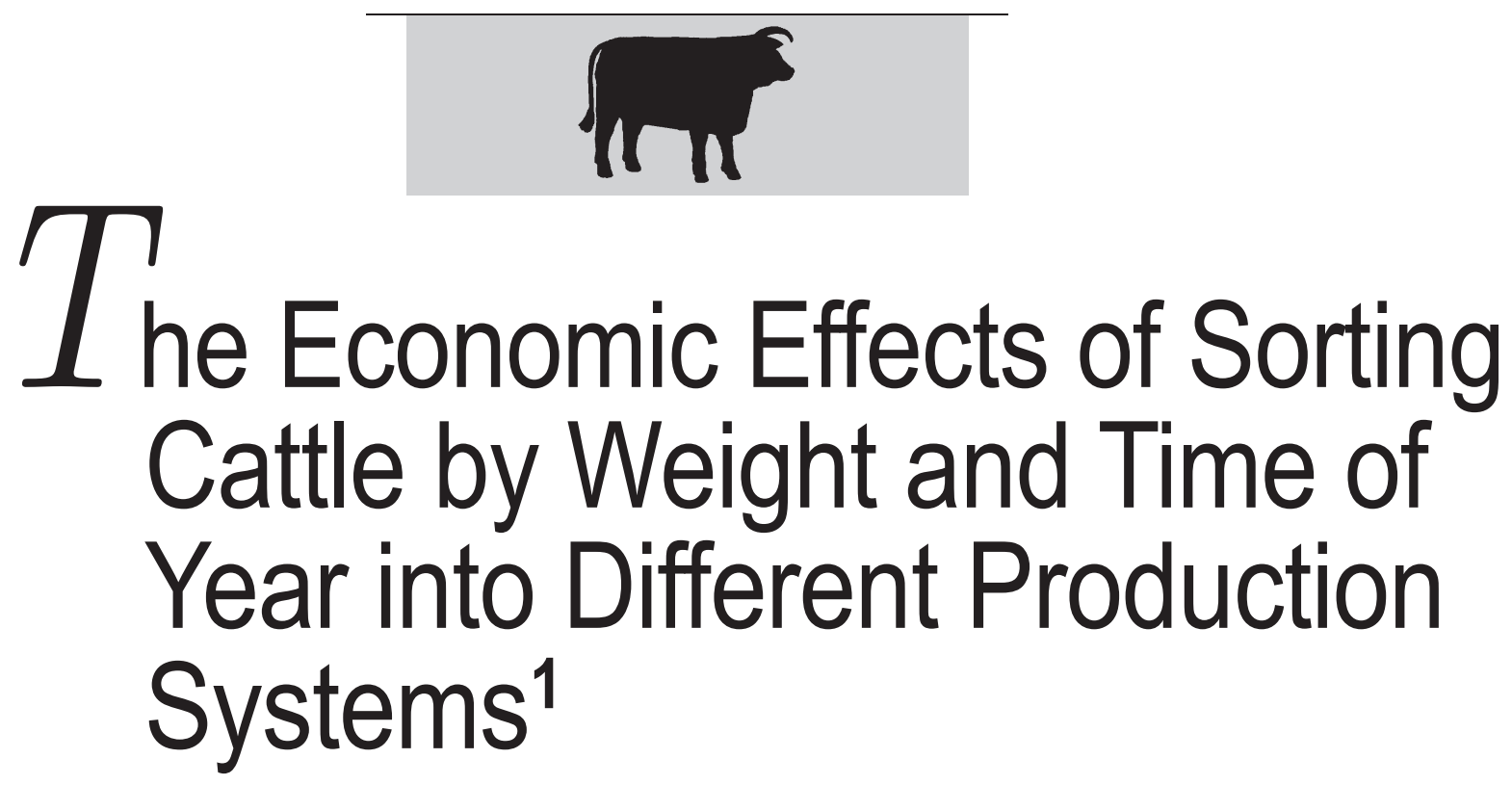

\author{
D. R. Adams, T. J. Klopfenstein, ${ }^{2}$ G. E. Erickson, PAS, D. R. Mark, M. K. Luebbe, \\ and W. A. Griffin, PAS \\ Department of Animal Science, University of Nebraska, Lincoln 68583
}

\begin{abstract}
A 2-yr study using 288 steers each year was conducted to determine the economic effects of sorting and feeding genetically similar cattle in different production systems. Steers were purchased at weaning in November and assigned randomly into sorted or unsorted groups. Unsorted steers were assigned randomly to 1 of 3 production systems: calf-fed steers (enter feedlot after weaning), summer yearling, or fall yearling; $n=$ 48 steers per system yearly. For sorted steers, the heaviest third were calf fed and the remaining steers grazed cornstalks during winter. After winter grazing, the heaviest half of those steers were fed as summer yearlings, and the lightest half were fed as fall yearlings. Initial steer price was calculated using breakeven analysis for sorted calf-fed steers, and all other profits and losses are relative to sorted calf-fed steers, with a defined profit of $\$ 0 /$ steer. Steer values were determined using 2007 average prices.
\end{abstract}

\footnotetext{
${ }^{1}$ A contribution of the University of Nebraska Agricultural Research Division, supported in part by funds provided through the Hatch Act.

${ }^{2}$ Corresponding author: tklopfen@unlnotes. unl.edu
}

Initial steer costs were greatest for sorted calf-fed steers and lowest for sorted fall yearlings. There were 2-way and a 3-way interaction for profit/loss. In yr 1, fall yearling gains on grass were normal, and the sorted fall yearlings were more profitable than were the sorted calf-fed steers. The reverse was true in the second year, when pasture gains of the fall yearlings were below normal. Marketing cattle on a grid decreased profit of summer yearlings because of low $Q G$ and decreased profitability of unsorted fall yearlings because of overweight carcasses. For the overall system, sorting did not increase profit on either a live or a grid-based marketing system.

Key words: feedlot cattle, productions system, profit, sorting

\section{INTRODUCTION}

Many factors affect the profitability of feeding cattle (Mark et al., 2002).

Because there are many factors, many different production systems can be used to maximize profit when feeding cattle. Because some land may not be suitable for tillage or forage harvesting (Oltjen and Beckett, 1996), it provides an alternative way to add $\mathrm{BW}$ and maintain a sustainable agriculture production system. Because cattle are diverse in terms of BW and frame size (Dolezal et al., 1993), it is important to match cattle to the correct production system to maximize profitability when feeding cattle. At the time of weaning, heavier cattle can be placed into an intensive system to minimize overweight carcasses (Griffin et al., 2007). Vieselmeyer (1993) indicated that if larger, heavier cattle are placed into an extensive (forage-based) system, the potential for overweight carcasses exists. Turgeon (1984) indicated that if smaller, lighter cattle entered the intensive system, it resulted in lighter carcass weights leading to decreased profitability. This is important because BW is a major economic driver in cattle production (Feuz, 2002; Shain et al., 2005). With the current fluctuations in corn prices (Mark and Malchow, 2008; Winterholler et al., 2008), finding the most profitable way to increase cattle BW becomes more important. Previous research has shown that profitability favors yearling production systems compared with calf-fed systems (Griffin et al., 2007). However, Winterholler et al. (2008) indicated that calf-fed steers were more profitable than yearlings that grazed wheat pasture 
Table 1. Simple effects of sorting, production system, and year on steer performance ${ }^{1,2}$

\begin{tabular}{|c|c|c|c|c|c|c|c|c|c|c|c|c|}
\hline \multirow[b]{3}{*}{ Item $^{3}$} & \multicolumn{6}{|c|}{ Yr 1} & \multicolumn{6}{|c|}{ Yr 2} \\
\hline & \multicolumn{3}{|c|}{ Sorted } & \multicolumn{3}{|c|}{ Unsorted } & \multicolumn{3}{|c|}{ Sorted } & \multicolumn{3}{|c|}{ Unsorted } \\
\hline & Calf & Summ & Fall & Calf & Summ & Fall & Calf & Summ & Fall & Calf & Summ & Fall \\
\hline INT, kg & 296 & 274 & 233 & 274 & 260 & 270 & 273 & 245 & 232 & 248 & 248 & 249 \\
\hline FINT, kg & 316 & 373 & 428 & 275 & 374 & 457 & 273 & 349 & 361 & 248 & 342 & 385 \\
\hline $\mathrm{FIN}, \mathrm{kg}$ & 573 & 623 & 632 & 559 & 624 & 672 & 573 & 613 & 626 & 555 & 609 & 653 \\
\hline$A D G, \mathrm{~kg} / \mathrm{d}$ & 1.69 & 1.88 & 1.76 & 1.71 & 1.88 & 1.85 & 1.53 & 1.83 & 2.01 & 1.57 & 1.84 & 2.03 \\
\hline DMI, kg/d & 9.8 & 11.7 & 12.4 & 9.5 & 11.6 & 13.1 & 9.2 & 11.3 & 12.3 & 8.8 & 11.2 & 13.2 \\
\hline Days fed & 167 & 133 & 116 & 167 & 133 & 116 & 196 & 145 & 132 & 196 & 145 & 132 \\
\hline Fat thickness, $\mathrm{cm}^{2}$ & 1.18 & 1.39 & 1.14 & 1.18 & 1.26 & 1.16 & 1.6 & 1.5 & 1.26 & 1.47 & 1.45 & 1.36 \\
\hline $\mathrm{HCW}, \mathrm{kg}$ & 377 & 392 & 398 & 352 & 393 & 423 & 361 & 387 & 394 & 350 & 384 & 412 \\
\hline $\mathrm{HCW}>432 \mathrm{~kg},{ }^{4} \%$ & 6.5 & 4.2 & 10.7 & 2.1 & 18.8 & 41.7 & 0 & 0 & 2.1 & 0 & 2.1 & 29.2 \\
\hline $\mathrm{HCW}>455 \mathrm{~kg}^{5} \%$ & 2.4 & 0 & 2.1 & 0 & 2.1 & 22.9 & 0 & 0 & 0 & 0 & 2.1 & 10.4 \\
\hline Choice, \% & 76.2 & 52.1 & 72.3 & 85.4 & 45.8 & 81 & 89.6 & 77.1 & 77 & 78.9 & 65.5 & 81.3 \\
\hline YG 4, \% & 8.3 & 14.6 & 10.4 & 0 & 11 & 12.5 & 30.1 & 31.3 & 13.7 & 21.4 & 31.3 & 22.9 \\
\hline
\end{tabular}

${ }^{1}$ Adapted from Adams et al. (2010).

${ }^{2}$ Calf = steers finished in the calf-fed system; Summ = steers that were allowed to winter graze cornstalks before entering the feedlot;

Fall = steers that winter grazed cornstalks and summer grazed native range before entering the feedlot.

${ }^{3} \mathrm{INT}=$ initial steer BW; FINT = BW at feedlot entry; FIN = final live BW (calculated using a 63\% dressing percentage); HCW = hot carcass weight.

${ }^{4}$ Percentage of carcasses over $432 \mathrm{~kg}$.

${ }^{5}$ Percentage of carcasses over $455 \mathrm{~kg}$.

before entering the feedlot. However, in a study by Winterholler et al. (2008), the average corn price was $\$ 2.15 / 25.4 \mathrm{~kg}$. When the price was increased to $\$ 3.76 / 25.4 \mathrm{~kg}$, profitability shifted toward the yearling system. Therefore, the objective of this study was to compare the economic benefits of sorting steers into different feeding systems by analyzing 1) live versus grid pricing, 2) time of year cattle were finished, and 3) sorting versus not sorting cattle into feeding systems using a $\$ 4 / 25.4 \mathrm{~kg}$ corn price.

\section{MATERIALS AND METHODS}

\section{Experiment}

Two years of data (Adams et al., 2010) from the University of Nebraska-Lincoln were used to evaluate production system economics. Each year at trial initiation in November, cattle were limit fed ( $2 \%$ of BW) a basal diet of $50 \%$ wet corn gluten feed
(Sweet Bran, SB; Cargill, Blair, NE) and $50 \%$ alfalfa hay (DM basis) for 5 consecutive days. After limit feeding, 2-d limit-fed BW were collected. After the first day weights, cattle were assigned randomly to either a sorted ( $\mathrm{n}=144 / \mathrm{yr})$ or unsorted group (n $=144 / \mathrm{yr}$ ). The unsorted group was then assigned randomly to 1 of 3 production systems (calf-fed steers, summer yearlings, or fall yearlings; $n$ $=48$ steers (system yearly). For the sorted group, the heaviest third of the steers were placed into the calf-fed system. The remaining two-thirds of the sorted steers grazed cornstalks during the winter months. At the end of winter grazing, these steers were limit fed ( $2 \%$ of BW) a basal diet of $50 \% \mathrm{SB}$ and $50 \%$ alfalfa hay (DM basis) for 5 days. After limit feeding, BW was measured. The heaviest half of these steers (one-third of the sorted steers) was placed into the summer yearling system, and the lightest half was assigned to the fall yearling system. Data were collected for the winter grazing period, summer grazing period, and finishing period. Feeding performance from this study is described by Adams et al. (2010). Economic comparisons were made for the different phases of the production systems. Performance data from Adams et al. (2010) are presented in Table 1.

For each system within year, days on feed was determined based on when steers in this study were estimated to have $1.14-$ to $1.27-\mathrm{cm}$ rib fat thickness and achieved a Choice QG. Estimation of fat thickness for cattle in this study was determined from previous research in which similar cattle were fed (MacDonald et al., 2006; Griffin et al., 2007; Folmer et al., 2008). There were differences in steer BW at the start of each year of the study and at the end of the grazing season for yearlings (Table 1). Dif- 


\section{Table 2. Dressed price/45.4 kg adjusted for live price and a base grid price along with premiums and discounts per $45.4 \mathrm{~kg}$ used to determine final grid value}

\begin{tabular}{l} 
Item \\
\hline Fed cattle prices \\
2007 average dressed price, $\$ / 45.4 \mathrm{~kg}$ \\
Adjusted live price, ${ }^{\$} \$ / 45.4 \mathrm{~kg}$ \\
Grid price \\
Grid base price, ${ }^{2} \$ / 45.4 \mathrm{~kg}$ \\
Premiums and discounts, $\$ / 45.4 \mathrm{~kg}$ \\
Prime \\
Upper $2 / 3$ Choice \\
Low Choice \\
Select \\
Standard \\
YG 1 \\
YG 2 \\
YG 3 \\
YG 4 \\
YG 5 \\
Carcasses over $431 \mathrm{~kg}$ \\
Carcasses over $454 \mathrm{~kg}$
\end{tabular}

Price, \$

${ }^{1}$ Calculated by multiplying the 2007 average dress price by a $63 \%$ dress.

${ }^{2}$ Grid base price is a Choice YG 3 carcass. ferences in steer BW led to differences in days on feed between yr 1 and 2 . In yr 1, calf-fed steers, summer yearlings, and fall yearlings were fed for 167 , 133 , and $116 \mathrm{~d}$, respectively. In yr 2, calf-fed steers, summer yearlings, and fall yearlings were fed for 196, 145, and $132 \mathrm{~d}$, respectively. Days on feed was similar for sorted and unsorted cattle.

\section{Economic Analysis}

The profit potential of the 3 production systems was examined under 3 scenarios: live versus grid pricing, time of year the cattle were finished, and sorted versus unsorted. Our objective was to study the effect of the production system (biology) on economics. Therefore, average annual prices were used. Obviously, time of year that cattle are purchased or sold or when feedstuffs are purchased would affect the economics. Nevertheless, because our objective was to study the effect of the biology on the economics, yearly average prices were used. All estimations of profit and loss are relative to the sorted calf-fed steers within year because the profit was netted to zero by selecting a maximum purchase price for the steers that would result in a breakeven profit. For the sorted calf-fed steers, the maximum purchase price was calculated by subtracting all costs from the final live price. Total costs included feed cost, yardage, death loss, health cost, and interest. The amount remaining was the maximum amount that could be spent to purchase the animal that, when divided by the BW of the animal at receiving, resulted in the breakeven price per kilogram for a 316- and 273-kg steer in yr 1 and 2 , respectively. The calculation allows the comparison to be made relative to the sorted calf-fed steers using the average 2007 dressed price (Mark and Malchow, 2008) multiplied by 0.63 to determine the final live price for the cattle (Table 2). Revenue and costs were determined by using 2007 prices (Table 2), from which the price for the sorted calf-fed steers was determined. After the feeder cattle price was calculated for the sorted calf-fed steers, a feeder cattle price slide was calculated (Dhuyvetter et al., 2001) assuming a corn price of $\$ 4 / 25.4 \mathrm{~kg}$ to value the feeder cattle in the unsorted and yearling system groups. The slide was based on feeder cattle BW, corn price, and predicted fed cattle price (Dhuyvetter et al., 2001). The price slide was used to determine feeder cattle prices for different weights of feeder cattle, which ranged from 204 to $340 \mathrm{~kg}$ (Table 3 ). The prices from the price slide were then used to calculate initial steer cost.

Total cost for the finishing period for all 3 production systems was calculated in the same way. The price of the feedlot diet was $\$ 0.1980 / \mathrm{kg}$ for yr 1 and $\$ 0.1802 / \mathrm{kg}$ for yr 2 . The diets were different between years but were the same within year. In yr 1, the diet was $33.75 \%$ high-moisture corn, $33.75 \%$ dry-rolled corn, $15 \%$ wet distillers grains plus solubles, $7.5 \%$ alfalfa, $5 \%$ molasses, and $5 \%$ supplement, all on a DM basis. Corn was priced at $\$ 4 / 25.4 \mathrm{~kg}$ with a processing fee added to the high-moisture corn and dry-rolled corn (Macken et al., 2006). Wet distillers grains plus solubles were priced at $80 \%$ of the price of corn on a DM basis. Alfalfa hay prices were obtained from Mark and Malchow (2008) using the 2007 average price. The molasses price was calculated from the USDA-reported 2007 average price (USDA, 2008). Supplement was included in the diet at a cost of $\$ 264 /$ t. The only difference in the ration from yr 1 to yr 2 was that wet distillers grains plus solubles was included at $20 \%$ of the

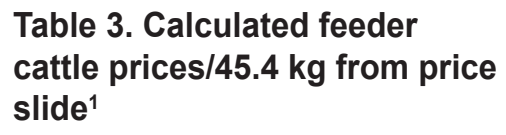

Table 3. Calculated feeder cattle prices $/ 45.4 \mathrm{~kg}$ from price slide $^{1}$

\begin{tabular}{lc} 
Weight, kg & Price, $\$ \mathbf{4 5 . 4} \mathbf{~ k g}$ \\
\hline 204 & 122.39 \\
249 & 112.06 \\
295 & 107.26 \\
340 & 103.25 \\
\hline
\end{tabular}

${ }^{1}$ Adapted from Dhuyvetter et al. (2001). 
diet DM in yr 2 and molasses was removed from the diet. Feed cost was calculated as price per kilogram and multiplied by the total kilograms consumed. Interest on half the feed cost and yardage was added to the cost of feed using an annual interest rate of $7.6 \%$. Yardage cost was assessed at a rate of $\$ 0.40$ per steer daily while in the feedlot. Health costs for all steers were charged at a flat rate of $\$ 24.99$ per steer, which included processing cost and an average of one medical treatment per steer. In all systems, $2 \%$ death loss was assumed; however, in the calf-fed steers, the death loss was charged at the beginning of the finishing period using initial steer cost. For summer yearlings, the death loss was split through each phase of production, calculating $1.5 \%$ death loss before feedlot entry from initial steer cost and $0.5 \%$ death loss at feedlot entry, which included initial steer cost and production charges during the growing phase. For fall yearlings, death loss was calculated by using $1.5 \%$ death loss in the winter phase, $0.3 \%$ death loss in the summer phase, and $0.2 \%$ death loss in the finishing phase.

The summer yearlings and fall yearlings had additional costs for grazing cornstalks and grass (Table 4). Yardage cost for grazing cornstalks was $\$ 0.32 /$ steer daily. This included $\$ 0.12$ /steer daily for stalk rent and $\$ 0.20 /$ steer daily for labor and upkeep of the fields. There was also a feed cost because the cattle were supplemented $2.27 \mathrm{~kg} /$ steer daily of SB while grazing cornstalks. The price of SB was calculated as $95 \%$ the price of corn on a DM basis. Interest was added to half of the cornstalk cost and feed cost. Grass intake during summer grazing was calculated by taking the average BW of the steers on grass divided by $454 \mathrm{~kg}$ to determine animal units (AU). One AU is equal to 454 kg (Meyer et al., 2008). That number was then multiplied by the number of days on grass divided by 30 to get the animal unit month (AUM) for each steer. The total AUM used were then multiplied by the 2007 Nebraska state average cost of an AUM (Johnson and Raymond, 1993-2007). A yardage charge of $\$ 0.10$ /steer daily was also applied to factor in labor cost while maintaining the steers on grass. Interest for half of the grass cost was also added into the total pasture cost before entering the feedlot. Adding all of the costs for cornstalks and grass to the initial steer cost gives the cost of the steer entering the feedlot after being backgrounded. The final live price of the steer minus all costs gives the profit or loss of the animal if it is sold on a live BW basis.

To calculate the grid price received, the average 2007 dressed price was used (Mark and Malchow, 2008). That price was added to one minus the percent Choice multiplied by the Choice-Select spread (Table 2). The base grid price multiplied by the carcass weight gives the grid price received for the steer. A grid formula with a base Choice YG 3 carcass was used. Discounts were given for carcasses with a QG less than low Choice along with YG 4 and 5 carcasses, and a 2-tier discount was given for overweight carcasses (431 and $454 \mathrm{~kg}$ ). Premiums were awarded for carcasses grading better than low Choice QG and carcasses that were YG 1 or 2 . Premiums and discounts are shown in Table 2. The averages used were obtained from the USDA (1997-2007). The dressed price was then adjusted up or down based on the QG and YG of the steers to determine the final grid price received. To calculate grid marketing profitability, the total cost of production was subtracted from the grid value of the steer.

\section{Statistical Analysis}

Data from this study were analyzed as a completely randomized design using a 2 (year) $\times 2$ (sorted vs. unsorted) $\times 3$ (production system) factorial arrangement of treatments. Data were analyzed using the mixed procedure of SAS (SAS Inst. Inc. Cary, NC). Pen was the experimental unit in this study. The model included feeding period, sorting treatment, year, feeding period by sorting treatment, feeding period by year, sorting treatment by year, and feeding period by sorting treatment by year. Least squares means were separated using the least significant difference method when a significant $(P<0.05)$ treatment $F$-test was detected.

\section{RESULTS AND DISCUSSION}

In this study, cattle were either assigned randomly or sorted by BW into different production systems. Compared with other sorting studies (MacDonald et al., 2006; Folmer et al., 2008; Griffin et al., 2009) in which cattle had a sorting strategy imposed on them at feedlot entry, the current study evaluated the effect of sorting cattle into production systems by BW with no other sorting treatment at feedlot entry. Therefore, days on feed was held constant for sorted and unsorted cattle in the different production systems because cattle were not sorted into different BW classes at feedlot entry. In addition, the goal was to finish cattle to an equal degree of fatness within system.

By design, initial steer cost differed between feeding systems for the sorted groups $(P<0.01)$. In both years, calf-fed steers had the highest initial cost even though cost per kilogram was less. In yr 1, sorted calf-fed steers cost $\$ 61.87$ and $\$ 118.89$ per steer more than sorted summer yearlings and sorted fall yearlings, respectively. In yr 2, sorted calf-fed steers were $\$ 51.98$ per steer more than sorted summer yearlings and $\$ 70.69$ per steer more than sorted fall yearlings (Table 4). By design, initial costs of the unsorted groups were similar within year. These data are consistent with previous research by Griffin et al. (2007). The initial cost was related to the sorted calf-fed steers having a greater initial BW at the time of receiving and the price slide employed. The sorted fall yearlings were then the lightest steers at time of arrival to the research feedlot. The summer yearlings would then be expected to be intermediate, which these data support.

Winter cost for grazing cornstalks was the same for summer and fall 
Table 4. Simple effects of sorting, production system, and year on the economics of production systems $(\$ /$ steer) $)^{1,2}$

\begin{tabular}{|c|c|c|c|c|c|c|c|c|c|c|c|c|}
\hline \multirow[b]{3}{*}{ Item } & \multicolumn{6}{|c|}{ Yr 1} & \multicolumn{6}{|c|}{ Yr 2} \\
\hline & \multicolumn{3}{|c|}{ Sorted } & \multicolumn{3}{|c|}{ Unsorted } & \multicolumn{3}{|c|}{ Sorted } & \multicolumn{3}{|c|}{ Unsorted } \\
\hline & Calf & Summ & Fall & Calf & Summ & Fall & Calf & Summ & Fall & Calf & Summ & Fall \\
\hline $\mid$ Initial $^{3}$ & 701.72 & 639.85 & 582.83 & 649.21 & 647 & 622.31 & 684.55 & 632.57 & 613.86 & 637.27 & 637.94 & 638.66 \\
\hline Winter ${ }^{4}$ & 0 & 111.47 & 111.47 & 0 & 111.47 & 111.47 & 0 & 112.55 & 112.55 & 0 & 112.55 & 112.55 \\
\hline Summer ${ }^{5}$ & 0 & 28.41 & 122.26 & 0 & 28.43 & 131.28 & 0 & 37.33 & 115.52 & 0 & 36.53 & 123.39 \\
\hline Feed cost & 322.97 & 308.28 & 284.49 & 314.41 & 305.9 & 301.85 & 326.33 & 295.84 & 291.38 & 309.99 & 291.94 & 314.43 \\
\hline Yardage $^{6}$ & 66.8 & 53.2 & 46.4 & 66.8 & 53.2 & 46.4 & 78.4 & 58 & 52.8 & 78.4 & 58 & 52.8 \\
\hline Interest $^{7}$ & 33.59 & 53 & 62.53 & 30.9 & 53.45 & 66.49 & 36.7 & 54.41 & 66.5 & 34.51 & 54.72 & 68.69 \\
\hline Total cost & $1,179.79$ & $1,243.84$ & |,261.79 & $1,097.59$ & 1249.14 & $1,333.26$ & $1,164.16$ & $1,243.83$ & $1,307.99$ & $1,097.32$ & $1,244.65$ & $1,367.71$ \\
\hline Live $^{8}$ & $1,179.77$ & $1,267.63$ & , 286.3 & $1,139.1$ & $1,270.8$ & $1,367.48$ & $1,164.13$ & $1,246.01$ & $1,271.14$ & $1,127.59$ & $1,237.49$ & $1,327.14$ \\
\hline Grid $^{9}$ & $1,227.51$ & $1,251.02$ & |,290.71 & $1,169.62$ & $1,236.23$ & $1,346.79$ & $1,169.6$ & $1,228.73$ & $1,289.76$ & $1,137.41$ & $1,204.94$ & $1,305.38$ \\
\hline Live $P / L^{10}$ & -0.03 & 23.78 & 24.51 & 41.51 & 21.67 & 34.22 & -0.03 & 2.18 & -36.85 & 30.26 & -7.17 & -40.57 \\
\hline Grid $P / L^{10}$ & 47.27 & 7.18 & 28.92 & 72.03 & -12.92 & 13.52 & 5.44 & -15.1 & -18.23 & -39.72 & 2.94 & -62.33 \\
\hline
\end{tabular}

${ }^{1} P$-values and SEM are presented in Table 5.

${ }^{2}$ Calf = steers finished in the calf-fed system; Summ = steers that were allowed to winter graze cornstalks before entering the feedlot;

Fall $=$ steers that winter grazed cornstalks and summer grazed native range before entering the feedlot.

Initial $=$ initial steer cost.

${ }^{4}$ Winter $=$ cost of winter grazing cornstalks.

${ }^{5}$ Summer $=$ cost of summer grazing native range.

${ }^{6}$ Yardage $=$ yardage cost during the finishing period $(\$ 0.40 /$ steer daily $) .{ }^{7}$ Interest $=$ interest accrued for the total time that steers were owned.

${ }^{8}$ Live $=$ value of the steer if marketed on a live basis

${ }^{9} \mathrm{Grid}=$ value of the steer if marketed on a grid .

${ }^{10} \mathrm{P} / \mathrm{L}=$ profit or loss.

yearlings within year but different between years $(P<0.01$; Table 4$)$. The difference between years, a cost of $\$ 1.08$ per steer, was due to the extra grazing days in yr 2 compared with yr 1 . The summer and fall yearlings were managed as one group while grazing cornstalks. Because steers were managed as one group during the winter, winter cost would not be different between groups.

Summer costs were different $(P<$ 0.01 ; Table 4 ) between summer and fall yearlings because of the number of days summer (35 and $48 \mathrm{~d}$ in yr 1 and 2, respectively) and fall (149 and 152 $\mathrm{d}$ in yr 1 and 2, respectively) yearlings grazed. The difference in summer cost for summer yearlings between the $2 \mathrm{yr}$ was due to more grazing days in yr 2 .
However, fall yearlings had lower summer cost in yr 2 because of differences in forage intake (calculated using animal BW; Meyer et al., 2008). In yr 2, steers had lighter average BW during the summer grazing season leading to less cost even though fall yearlings grazed for $148 \mathrm{~d}$ in yr 1 and $153 \mathrm{~d}$ in yr 2 . The difference between the summer cost of sorted and unsorted fall yearlings was due to differences in BW during the summer grazing season. The summer cost was calculated based on AUM, which is based on the $\mathrm{BW}$ of the animals grazing (Meyer et al., 2008). The unsorted fall yearlings had a higher cost both years because they were heavier at the time of grazing.
There was a feeding period by sorting treatment interaction $(P<0.01)$ and a feeding period by year interaction $(P=0.02)$ for feedlot feed cost (Tables 4 and 5). When evaluating the feeding period by sorting interaction, sorted calf-fed steers had the highest feed cost and sorted fall yearlings had the lowest feed cost each year. All other groups were intermediate and similar when comparing feed costs. These costs reflect the total feed that was consumed by the different groups. In yr 2, total feed intake for unsorted fall yearlings was greater than that for the calf-fed steers while in the feedlot. The fall yearlings were in the feedlot fewer days but had a higher daily DMI, which resulted in the unsorted fall yearlings eat- 
Table 5. Statistical $P$-values for the economics presented in Table 4

\begin{tabular}{|c|c|c|c|c|c|c|c|c|}
\hline Item & SEM & TRT $^{1}$ & Type $^{2}$ & $Y r^{3}$ & Type $\times$ TRT $^{4}$ & $\mathrm{TRT} \times \mathrm{Yr}^{5}$ & Type $\times Y^{6}{ }^{6}$ & Type $\times$ TRT $\times{Y Y r^{7}}^{7}$ \\
\hline$|n i t i a|^{8}$ & 3.67 & $<0.01$ & $<0.01$ & 0.23 & $<0.01$ & 0.64 & $<0.01$ & $<0.01$ \\
\hline Feed Cost & 5.44 & 0.63 & $<0.01$ & 0.67 & $<0.01$ & 0.85 & 0.02 & 0.68 \\
\hline Yardage $^{9}$ & 0 & $<0.01$ & - & $<0.01$ & - & - & $<0.01$ & - \\
\hline Interest ${ }^{10}$ & 0.32 & 0.02 & $<0.01$ & $<0.01$ & $<0.01$ & 0.42 & $<0.01$ & 0.3 \\
\hline Total cost & 7.75 & 0.66 & $<0.01$ & 0.03 & $<0.01$ & 0.97 & $<0.01$ & 0.45 \\
\hline Live $^{11}$ & 12.07 & 0.2 & $<0.01$ & $<0.01$ & $<0.01$ & 0.44 & 0.64 & 0.69 \\
\hline Grid $^{12}$ & 13.56 & 0.23 & $<0.01$ & $<0.01$ & $<0.01$ & 0.62 & 0.43 & 0.23 \\
\hline Live $P / L^{13}$ & 9.2 & 0.05 & $<0.01$ & $<0.01$ & $<0.01$ & 0.32 & $<0.01$ & 0.97 \\
\hline Grid $P / L^{13}$ & 12.88 & 0.3 & $<0.01$ & $<0.01$ & $<0.01$ & 0.6 & 0.11 & 0.54 \\
\hline
\end{tabular}

${ }^{1}$ Sorted/unsorted effect.

${ }^{2}$ Feeding period effect.

${ }^{3}$ Year effect.

${ }^{4}$ Sorted/unsorted by feeding period effect.

${ }^{5}$ Sorted/unsorted by year effect.

${ }^{6}$ Feeding period by year effect.

${ }^{7}$ Sorted/unsorted by feeding period by year effect.

${ }^{8}$ Initial $=$ initial steer cost.

${ }^{9}$ Yardage $=$ yardage cost during the finishing period $(\$ 0.40 /$ steer daily).

${ }^{10}$ Interest $=$ interest accrued for the total time that steers were owned.

${ }^{11}$ Live $=$ value of the steer if marketed on a live basis.

${ }^{12} \mathrm{Grid}=$ value of the steer if marketed on a grid.

${ }^{13} \mathrm{P} / \mathrm{L}=$ profit or loss.

ing a larger amount of feed. The fall yearlings had a higher ADG and were not as efficient as the calf-fed steers. Greater consumption in yr 2 was due to fall yearlings having poor pasture gains, leading to decreased $\mathrm{BW}$ at feedlot entry, which required more days on feed to maximize BW gain and market steers with back fat depth of $1.26 \mathrm{~cm}$ at the $12 \mathrm{th}$ rib. The feeding period by year interaction was due to the different days on feed for the fall yearlings between the years.

Because sorted and unsorted cattle within each production system were marketed at similar days fed, yardage costs were the same for the sorted and unsorted groups within a year (Tables 4 and 5). The sorted and unsorted steers within production system were fed the same number of days within a year but a different number of days between the 2 years; therefore, yardage cost was greater in yr $2(P<$
0.01). The steers in yr 2 were fed for more days for all 3 feeding systems.

When interest was calculated, the calf-fed steers always had the lowest interest compared with the summer and fall yearlings. The fall yearlings had the greatest interest cost $(P<$ 0.01 ; Tables 4 and 5$)$. This was expected because the calf-fed steers were owned for the shortest amount of time and the fall yearlings were owned for the greatest amount of time.

There was a feeding period by sorting treatment interaction $(P<0.01)$ for final live value (Tables 4 and 5 ). The final live value follows the same pattern as carcass weight (Adams et al., 2010), with the unsorted fall yearlings having the highest final live value followed by the sorted fall yearlings. The sorted and unsorted summer yearlings were not different, and the sorted calf-fed steers had greater final live value than did the unsorted calf-fed steers, which had the lowest final live value. The unsorted calf-fed steers were the lightest steers that entered the feedlot, resulting in the lightest carcasses. The unsorted fall yearlings had a greater final live value ( $\$ 71.47$ and $\$ 59.72 /$ steer in yr 1 and 2, respectively) compared with the sorted fall yearlings. This was because the final value was based on final BW, which was calculated from carcass weight. The final live value for the sorted calf-fed steers was $\$ 40.67$ and $\$ 36.54 /$ steer more than that for the unsorted calf-fed steers in yr 1 and 2, respectively. This was expected because the sorted calf-fed steers had 12-kg-heavier carcasses compared with the unsorted calf-fed steers.

Grid values follow the same pattern as the live price received for the steers $(P<0.01$; Tables 4 and 5$)$. The unsorted fall yearlings had the greatest grid value at the time of slaughter, 
followed by the sorted fall yearlings. Sorted and unsorted summer yearlings were not different. However, the sorted calf-fed steers had greater value compared with the unsorted calf-fed steers. This was expected because the base grid price is based on the carcass weight of the steers at slaughter. The premiums and discounts that are added change the amount received in grid-based marketing compared with live BW marketing.

For live profit/loss, there was a year by feeding period interaction $(P<$ 0.01 ; Table 5 ) and a sorting treatment by feeding period interaction $(P<0.01)$. In yr 1 , fall yearlings on average had a profit of $\$ 29.37$ / steer compared with $-\$ 38.71 /$ steer in yr 2. When considering profitability of sorted fall yearlings and sorted calffed steers, in yr 1, sorted fall yearlings were $\$ 24.54 /$ steer more profitable than sorted calf-fed steers. The opposite was true for yr 2 , with sorted calf-fed steers being $\$ 36.82 /$ steer more profitable compared with sorted fall yearlings. Considering only yr 1 , the data would support previous research (Griffin et al., 2007). Low profitability in yr 2 was due to poor gains during summer grazing. In yr 1, the fall yearlings had a pasture ADG of 0.81 $\mathrm{kg} / \mathrm{d}$ compared with yr 2 when pasture ADG was $0.31 \mathrm{~kg} / \mathrm{d}$. Folmer et al. (2008) reported a pasture ADG of $0.79 \mathrm{~kg} / \mathrm{d}$. In the current study, ADG in yr 1 was slightly more than that of Folmer et al. (2008), whereas in yr 2, steers exhibited ADG that were not even half of the value reported in yr 1 and by Folmer et al. (2008). Due to poor summer gains in yr 2, extra BW had to be put on during the finishing period of the system. This then increased the number of days on feed in the feedlot, ultimately increasing total cost of the production system. Unsorted calf-fed steers were more profitable (live basis) than fall yearlings both years (Table 4 and 5).

Summer yearlings were not influenced much by gains on grass because they grazed only $30 \mathrm{~d}$. In both years, sorted summer yearlings were more profitable (live basis) than sorted calf-fed steers, whereas unsorted calf- fed steers were more profitable than unsorted summer yearlings (Tables 4 and 5). Because of poor pasture gains in yr 2, fall yearlings were less profitable than summer yearlings. In yr 1 profit was similar among fall yearlings and summer yearlings. There was no difference in marbling score between the calf-fed steers and fall yearlings (Adams et al., 2010). Sainz and Vernazza Paganini (2004), Krehbiel et al. (2000), and Griffin et al. (2007) also showed that calf-fed steers and fall yearlings had no differences in USDA called marbling scores. The reduction in profit on a grid basis for the summer yearlings compared with calf-fed steers was due to summer yearlings grading only $59.7 \%$ Choice, which was lower than calf-fed steers. The calf-fed steers were the most profitable on a grid basis because of the premiums for QG and limited discounts for overweight carcasses (Tables 4 and 5). Profitability for fall yearlings was also affected because of the discounts for overweight carcasses, especially for unsorted cattle. The interaction for year by feeding period $(P<0.01)$ was very obvious given differences in summer grazing performance for fall yearlings and because of the large effect of overweight carcasses in unsorted cattle, which was different across years.

The marketing method (i.e., live or grid) used had a large effect on profit and loss. The sorted calf-fed steers exhibited the largest change in profit (\$26.39/steer) when comparing live to grid marketing, whereas the unsorted calf-fed steers decreased $\$ 19.73 /$ steer (Table 6). The summer yearlings were less profitable going from live to grid marketing. The sorted summer yearlings had a larger decrease in profit ( $-\$ 16.94 /$ steer) than did the unsorted summer yearlings ( $-\$ 12.24$ / steer) when switching from live to grid marketing. The main reason for the summer yearlings decreasing in profit was due to the cattle not grading USDA Choice or higher. The sorted fall yearlings had increased profit of $\$ 11.52 /$ steer when marketed using the grid compared with live marketing. However, the unsorted

\section{Table 6. Change in profit from live to grid marketing comparing sorted/unsorted by feeding period ${ }^{1}$}

\begin{tabular}{lc} 
Item & $\begin{array}{c}\text { Change in profit, } \\
\text { \$/steer }\end{array}$ \\
\hline Calf-fed steers & \\
Sorted & 26.39 \\
Unsorted & -19.73 \\
Summer & \\
yearlings & \\
Sorted & -16.94 \\
Unsorted & -12.24 \\
Fall yearlings & \\
Sorted & 11.52 \\
Unsorted & -21.23 \\
\hline
\end{tabular}

${ }^{1}$ Sorted cattle and unsorted cattle were fed the same number of days.

${ }^{2}$ Change in profit is live marketing profit subtracted from grid marketing profit.

fall yearlings when going from live to grid marketing lost $\$ 21.23 /$ steer. This decrease was due to the number of overweight carcasses in the unsorted group. When comparing the sorted to unsorted groups, the sorted groups, excluding summer yearlings, had a greater profit when going from a live value to grid marketing.

Sorting the cattle into 3 feeding periods based on BW is a logical method of matching BW and body size to feeding period and thereby minimizing discounts, especially overweight discounts (Table 1). Considering sorting as a system (main effect), the unsorted cattle had greater profit $(P<0.01)$ on a live basis compared with the sorted cattle at $\$ 13.32$ / steer and $\$ 2.26 /$ steer, respectively. This was due to the unsorted calf-fed steers being slightly more efficient than the sorted calf-fed steers. Shain et al. (2005) and Feuz (2002) indicated that BW is the major economic driver for beef production. On the grid basis, the sorted steers were only marginally $(P=0.32)$ more profitable $(\$ 9.25 /$ steer $)$ than the unsorted steers $(-\$ 4.41 /$ steer $)$. This was due to the discounts for overweight carcasses in the unsorted group. This analysis in- 
dicates sorting steers for a production system increased profit when steers were marketed live, and the numerical increase for the cattle sold on the grid was not significant. We assume all cattle are actually traded on a grid basis because the price offered by the packer buyer reflects the individual's evaluation of how well the cattle will meet grid requirements. The live price used herein assumes all cattle receive the average price, which is likely not the case, but no data are available to support variable prices other than obvious grid discounts and premiums.

\section{CONCLUSIONS}

Because pasture gains were poor in yr 2, data from yr 1 may be more representative for comparing a system of sorting cattle to an unsorted system. In yr 1, unsorted cattle sold live were $\$ 16.37$ more profitable than sorted cattle. Sorted cattle sold on a grid were only $\$ 3.58$ more profitable than unsorted cattle. These data do not support sorting cattle by BW into different production systems. Sorting decreased profitability for calf-fed steers or fall yearlings when they were sold live. Sorting increased profitability for summer yearlings. Sorting increased profit for summer and fall yearlings when they were sold on a grid. Summer grazing gains in an extensive production system are critical to profitability. Poor pasture gains before feedlot entry leads to a requirement of more days on feed, which increases production cost. The seasonality of cattle and grain prices has large influences on profitability; thus it is important to understand price fluctuation throughout the year.

\section{LITERATURE CITED}

Adams, D. R., T. J. Klopfenstein, G. E. Erickson, W. A. Griffin, M. K. Luebbe, M. A Greenquist, and J. R. Benton. 2010. Effects of sorting steers by body weight into calf-fed, summer yearling, and fall yearling feeding systems. Prof. Anim. Sci. 26:587.

Dhuyvetter, K. C., T. Schroeder, and W. Prevatt. 2001. The impact of corn and fed cattle prices on feeder cattle price slides. Kansas State Univ. Agric. Exp. Stn. Coop. Ext. Serv. Publ. MF-2504, Manhattan, KS.

Dolezal, H. G., J. D. Tatum, and F. L. William Jr. 1993. Effects of feeder cattle frame size, muscle thickness, and age class on days fed, weight, and carcass composition. J. Anim. Sci. 71:2975.

Feuz, D. M. 2002. A simulated market analysis of altering days on feed and marketing cattle on specific value-based pricing grids. Nebraska Beef Cattle Rep. MP 79-A:39.

Folmer, J. D., W. A. Griffin, C. N. Macken, M. P. Blackford, T. J. Klopfenstein, and G. E. Erickson. 2008. Effect of intensive winter management, partial season grazing, and sorting on performance and economics of a long yearlings production system. Prof. Anim. Sci. 24:411.

Griffin, W. A., T. J. Klopfenstein, G. E. Erickson, D. M. Feuz, J. C. MacDonald, and D. J. Jordon. 2007. Comparison of performance and economics of a long-yearling and calf-fed system. Prof. Anim. Sci. 23:490.

Griffin, W. A., T. J. Klopfenstein, G. E. Erickson, D. M. Feuz, K. J. Vander Pol, and M. A. Greenquist. 2009. Effect of sorting and Optaflexx supplementation on feedlot performance and profitability of long yearling steers. Prof. Anim. Sci. 25:273.

Johnson, B., and A. Raymond. 1993-2007. Nebraska farmland values. Husker Economics Ext. Publ., Univ. Nebraska, Lincoln.

Krehbiel, C. R., K. K. Kreikemeier, and C. L. Ferrell. 2000. Influence of Bos indicus crossbreeding and cattle age on apparent utilization of a high grain diet. J. Anim. Sci. 78:1641.

MacDonald, J. C., T. J. Klopfenstein, G. E. Erickson, C. N. Macken, J. D. Folmer, and M. P. Blackford. 2006. Sorting strategies for long yearling cattle grown in an extensive forage utilization beef production system. Prof. Anim. Sci. 22:225.
Macken, C. N., G. E. Erickson, and T. J. Klopfenstein. 2006. The cost of corn processing for finishing cattle. Prof. Anim. Sci. $22: 23$.

Mark, D. R., R. Jones, and J. Mintert. 2002. Seasonal trends in steer feeding profits, prices, and performance. Kansas State Univ. Agric. Exp. Stn. Coop. Ext. Serv. Publ. MF2547, Manhattan, KS.

Mark, D. R., and S. Malchow. 2008. Crop and livestock prices for Nebraska producers. Univ. Nebraska Ext. Publ., EC-883, Lincoln, NE.

Meyer, T. L., D. C. Adams, T. J. Klopfenstein, J. D. Volesky, L. A. Stalker, and R. N. Funston. 2008. Estimating livestock forage demand: Defining the animal unit. J. Anim. Sci. 86(E-Suppl. 3):165. (Abstr.)

Oltjen, J. W., and J. L. Beckett. 1996. Role of ruminant livestock in sustainable agricultural systems. J. Anim. Sci. 74:1406.

Sainz, R. D., and R. F. Vernazza Paganini. 2004. Effects of grazing and feeding periods on performance and carcass traits of beef steers. J. Anim. Sci. 82:292.

Shain, D. H., T. J. Klopfenstein, R. A. Stock, B. A. Vieselmeyer, and G. E. Erickson. 2005. Evaluation of grazing alternate summer and fall forages in extensive beef cattle production systems. Prof. Anim. Sci. 21:390.

Turgeon, O. A. 1984. Impact of high forage growing systems on finishing performance and compensatory growth. PhD Dissertation. Univ. Nebraska, Lincoln.

USDA. 1997-2007. USDA national steer \& heifer estimated grading percent report. Agric. Marketing. Serv., NW_LS196, various issues.

USDA. 2008. Average price paid for molasses. Accessed Apr. 2008, http://www.nass.usda. gov.

Vieselmeyer, B. A. 1993. Production and economic interactions of extensive beef production systems. MS Thesis. Univ. Nebraska, Lincoln.

Winterholler, S. J., D. L. Lalman, M. D. Hudson, C. E. Ward, C. R. Krehbiel, and G. W. Horn. 2008. Performance, carcass characteristics, and economic analysis of calf-fed and wheat pasture yearling systems in the southern great plains. Prof. Anim. Sci. $24: 232$ 